\title{
Prevalence of periodontitis and alveolar bone loss in a patient population at Harvard School of Dental Medicine
}

\author{
Mohammad F. Helmi ${ }^{1,2}$, Hui Huang ${ }^{3}$, J. Max Goodson ${ }^{4,5}$, Hatice Hasturk ${ }^{5}$, Mary Tavares ${ }^{2}$ and Zuhair S. Natto ${ }^{6^{*}}$ (D)
}

\begin{abstract}
Background: Although several studies assessed the prevalence of alveolar bone loss, the association with several risk factors has not been fully investigated. The aim of this article is to measure the prevalence of periodontitis by calculating the mean alveolar bone loss/level of posterior teeth using bitewing radiographs among the patients enrolled in the clinics at Harvard School of Dental Medicine and address risk factors associated with the disease.

Methods: One thousand one hundred thirty-one patients were selected for radiographic analysis to calculate the mean alveolar bone loss/level by measuring the distance between the cementoenamel junction and the alveolar bone crest on the mesial and distal surfaces of posterior teeth. Linear regression with Multi-level mixed-effect model was used for statistical analysis adjusting for age, sex, race, median household income, and other variables.

Results: Mean alveolar bone level of the whole sample was $1.30 \mathrm{~mm}( \pm 0.006)$. Overall periodontitis prevalence for the sample was $55.5 \%( \pm 1.4 \%)$. Moderate periodontitis prevalence was $20.7 \%( \pm 1.2 \%)$, while $2.8 \%( \pm 0.5 \%)$ of the whole sample had severe periodontitis. Adjusted mean alveolar bone loss was higher in older age groups, males, Asian race group, ever smokers, and patients with low median household income.

Conclusion: The effect of high household income on the amount of bone loss can be powerful to the degree that high household income can influence outcomes even for individuals who had higher risks of developing the disease. Public health professionals and clinicians need to collaborate with policy makers to achieve and sustain high quality of healthcare for everyone.
\end{abstract}

Keywords: Systemic diseases, Periodontal disease, Alveolar bone loss, Prevalence

\section{Background}

Periodontal diseases are inflammatory diseases of the oral cavity that can be confined only to the gingiva as in gingivitis or exceed beyond that to result in soft and hard tissue loss which affects the attachment of the teeth to the alveolar bone, as in periodontitis [1]. This is an inflammatory process that has been studied for decades with respect to its nature, risk factors, and whether it has specific or non-specific etiological factors including the underlying microbiology [2-5]. It is commonly found as a chronic state of disease that is characterized by slow bursts of progression of varying durations [6-9].

\footnotetext{
* Correspondence: z_world@hotmail.com

${ }^{6}$ Department of Dental Public Health, Faculty of Dentistry, King Abdulaziz University, Jeddah, Saudi Arabia

Full list of author information is available at the end of the article
}

However, other studies are still investigating the nature of periodontal diseases progression. Emerging evidence suggesting that both theories of progression, linear and burst theories, are manifestations of the same phenomena and occur simultaneously in the same patients $[10,11]$. Research continues to define all the factors participating in the initiation and progression of periodontal diseases. Cekici et al. published a report in 2015 discussing this particular inflammatory process and the mechanisms behind its occurrence [12]. The authors concluded, "... Physiologic inflammation is a well-orchestrated network of cells, mediators and tissues. It is very important to consider the inflammatory / immune response as a whole, rather than many different modules working separately. As disease appears to be the result of loss of regulation and a failure to return to homeostasis, it is important to achieve a more complete 
understanding of the molecular and cellular events in this complex system". Overall, periodontal diseases have common etiological factors and many risk factors predisposing disease initiation and progression [13, 14]. Several studies found that although periodontitis occurs in most age groups, it is more prevalent in older age groups and seniors [15-17]. Ethnicity and race also play a role in the individuals' susceptibility to periodontitis, with African Americans as more susceptible than other racial groups and ethnicities [18]. Some investigators have suggested that MexicanAmericans have the highest susceptibility to periodontal attachment loss [19]. Many studies have found that men have greater risk than women for advancing periodontal diseases $[15,16]$. Several studies have also reported that individuals with lower socioeconomic status are at greater risk of periodontitis $[15,16]$.

Other risk factors reported to be associated with periodontitis include oral hygiene status [20,21], smoking [22], and systemic diseases, particularly diabetes mellitus and cardiovascular diseases [22-24]. Evidence suggests that periodontitis and diabetes mellitus have two-way relationship with diabetes increasing the risk for periodontitis, and periodontal inflammation affecting the glycemic control in a negative way [25]. Debates continue on the nature of the relationship between systemic and periodontal diseases. In fact, it is still unclear in the literature including the investigators several aspects such as which came first, the pathogenesis, and treatment. Lewis et al., in 2017, published a review discussing the relationship between a number of systemic diseases and periodontitis and concluded that confounding prevents solid inference [26].

The National Institute of Dental and Craniofacial Research refers to periodontal diseases as the most common cause of tooth loss in adults [27]. In 2013, Marcenes et al. published a paper estimating the global burden of oral conditions from 1990 to 2010 [28]. In this paper, the disability adjusted life-years (DALYs) were measured, which is the sum of life years lost due to premature death and years lived with disabilities [29]. Based on this study, the global burden of oral conditions in 2010 affected nearly 4 billion people. Untreated dental caries of permanent dentition was ranked the first most prevalent condition affecting around 35\% of all humans. Severe periodontitis was ranked the sixth most prevalent condition affecting about 744 million individuals globally. Over this twenty-year period, DALYs due to severe periodontitis had the highest increase of all oral conditions by $57 \%$. Moreover, severe periodontitis is considered as the primary cause of DALYs in the age group of 35 to 59 year-old and accounted for more than five million DALYs globally, implying an average of 108 healthy life years per 100,000 people lost due to a preventable disease such as severe periodontitis. Such a high global burden of periodontal disease can have an undeniable negative impact on health, productivity, income, and overall quality of life.

Several studies have reported the prevalence of periodontitis in the United States. In 2015, Eke et al. published a paper using NHANES data from 2009 to 2012 finding that $46 \%$ of adults 30 years of age or older have periodontitis representing almost 65 million people with 9\% having severe periodontitis [16]. A second paper from this group was published in 2016 measuring the prevalence of periodontitis for seniors 65 years of age or older [17]. The overall prevalence of periodontitis was $66 \%$ for all seniors 65 years of age or older with males to be more significantly affected by severe periodontitis (16\%) compared to females (6\%).

The use of radiographs to assess alveolar bone loss appears frequently in the literature [18]. The rational for using bitewing (BW) radiographs is to minimize angular distortion. Only in BW films does the $\mathrm{x}$-ray beam penetrate perpendicularly through the teeth to the $\mathrm{x}$-ray film or sensor while at the same time being parallel to the occlusal plane. An ideal bitewing radiograph should provide a clear view of the mandibular and maxillary alveolar bone and teeth with minimal overlap of anatomical structures [30]. Radiographic beam angulation has been reported to affect the radiographic measurements by an amount of $\pm 1.6 \mathrm{~mm}$ comparing clinical and radiographic alveolar bone crest $[31,32]$. The use of non-standardized BW radiographs, however, was reported in the literature to have the ability to detect less than $1 \mathrm{~mm}$ alveolar bone change indicating its usefulness for monitoring periodontal diseases progression [30,33]. Studies that have used repeated radiograph measurements of the same sites have found a mean difference of $0.09 \mathrm{~mm}$ between the measurements suggesting a 9\% discrepancy for repeated radiographs [34]. The specific aim of this study was to measure the prevalence of periodontitis using BW radiographs among the patients enrolled in the clinics at Harvard School of Dental Medicine (HSDM) and investigate their risk factors associated with the disease, comparing them to predisposing factors reported in the literature.

\section{Methods}

The information technology (IT) team of HSDM performed a database search of up to 6265 patient records. The database search included completed comprehensive oral examinations and radiographs (either full mouth series or bitewing radiographs) for each individual patient who had a clinic visit between January 1, 2014 and December 31, 2015. Data were gathered from AxiUm, an electronic health records system at HSDM, including age, gender, body mass index (BMI), chronic medical conditions (diabetes, hypertension, cardiovascular diseases, etc.), tobacco use, race/ethnicity, as well as each patient's radiographs. The electronic health records did 
not contain information directly related to socioeconomic status (SES). To estimate SES we collected ZIP codes of all patients. Median income for each zip code was determined using U.S. Census Bureau statistics [35]. The patient pool was selected based on their age at their last appointment at HSDM. One examiner (MH) reviewed all 6265 patients and selected 2320 suitable patients for the study.

Exclusion criteria used were: 1) patients that were not within the specified age range, 2) patients with no BW radiographs, 3) patients with radiographs in which the cement-enamel junction (CEJ) and alveolar bone crest were not visible, 4) patients who did not have at least 2 approximating teeth or where the interproximal space was too narrow to observe the bone crest. Teeth were excluded if dental restorations obliterated the CEJ, rendering the distance between CEJ and alveolar crest questionable. Additionally, cases in which a tooth was found adjacent to an edentulous site with alveolar bone levels greater than $2 \mathrm{~mm}$ from the CEJ were not considered pathological due to possible surgical trauma. Any records indicating sites receiving osseous surgery or bone grafts were excluded. Third molar teeth were not included due to their tendency of not being captured by BW radiographs. Non-functional teeth were excluded for the possibility of super eruption. Alveolar bone loss/ level was measured on the mesial and distal sites of first and second mandibular and maxillary posterior teeth using the calibrated measuring tool of $\mathrm{Emago}^{\circ}$ (Oral Diagnostic Systems, Amsterdam, Netherlands) softwarethe radiographic imaging software at HSDM. Data will be available upon request. IRB approval was obtained through The Office of Human Research Administration, Harvard Faculty of Medicine, [45 CFR 46.101(b) [4]], Protocol \# IRB16-1838. The permission from the HDSM to access AxiUm was included in the ethical approval.

\section{Outcome assessment}

Radiographic indication of interproximal bone loss occurs when the distance between the CEJ and the alveolar bone crest is greater than or equal to $2 \mathrm{~mm}$, as determined on a bitewing radiograph [36-39]. Our primary outcome is the level of alveolar bone on mesial and distal sites of posterior teeth as a continuous variable. We also categorized amount of bone loss based on case definition by the American Academy of Periodontology (AAP) into mild, moderate, and severe periodontitis [39-41] to estimate the prevalence of each case definition for descriptive and baseline characteristics.

\section{Predictors}

Age: five categories of age were generated. Age groups of this study were defined as less than $30,30-34,35-49$, $50-64$, and 65 or more years old based on distribution of patients. Sex: binary variable of sex was coded 1 if the subject was male and 0 if subject was female. Race / Ethnicity: we generated 5 categories of the race variable based on patient self-reports. Categories included White, African American, Asian, Other, and Unknown. Since this was self reported, we did not have information about races that were reported as "Other". Patients with Hispanic ethnicity were few $(N=21)$; hence it was coded under "Other". BMI: based on patients' reported height and weight, BMI was calculated and then categorized into 4 groups using CDC criteria [42]. Systemic Diseases: medical history of three main systemic diseases was collected from the electronic health records which were mandatory to fill. These included cardiovascular disease (CVD), hypertension, and type 2 diabetes. CVD and diabetes were coded 1 if the patient had the diseases and 0 if they did not. For hypertension, we relied on systolic and diastolic blood pressure measured at the clinic and not on medical history reporting hypertension because the later had a high number of misclassification resulting in very few records that were consistent in reporting the disease. We used the new categories by the American College of Cardiology and the American Heart Association [43] to develop 4 categories- normal, elevated, stage 1 hypertension, and stage 2 hypertension. Smoking status: we generated 3 categories to describe smoking status. Patients that did not smoke were categorized as never smokers, and patients who reported that they were smoking were categorized as current smokers. Patients who reported that they were smokers and had quit smoking were categorized as former smokers. Median household income: Since income was not included in the patient database, we based this variable on the ZIP code for each patient and the associated estimates of household income that have been collected using U.S. Census Bureau, 2012-2016 American Community Survey 5-Year Estimates [35]. The variable was categorized into either higher than the sample median household income $(=1)$ OR equal or lower than the sample median household income (reference $=0$ ).

\section{Sample size}

To determine the adequate sample size, a power calculation was conducted. Based on a study conducted by Eke et al. in 2012, using similar age groups as the ones we used, the odds ratio of developing periodontitis was 2.315 comparing 35-49 year-old group to 30-34 yearold group, with a prevalence of total periodontitis of $36.6 \%$ [19], a sample size of $n=450$ was adequate to obtain a Type I error rate of $5 \%$ and power greater than $80 \%$. Based on the sample size calculations, each age group required a minimum of 90 patients; however, we conducted a random sample of 1300 out of the 2320 patients that were suitable for analysis and exceeded the 
minimum number of patients in each age category because we needed higher number of subjects in other categorical variables included. During the measurement process for all 1300 patients, 171 patients were excluded either due to closed electronic files or because their BW radiographs could not be calibrated with the measuring tool. The final number of patients that were included in the analysis was 1131 patients.

\section{Data analysis}

Descriptive statistics (means and standard deviations for continuous variables, counts and percentages for categorical variables) were calculated. The percentage of subjects with periodontal bone loss was computed for each age bracket. Statistical significance of the association between age and other predictors and periodontal bone loss was assessed via multi-level liner regression using mixed-effect model to estimate fixed-effect shared by the whole population and random-effect to account for variability between individuals and teeth examined. Sites measured are nested within teeth that are nested within individuals. Fixed-effect model estimates the grand mean of the population (intercept), and randomeffect model estimates the standard deviation (variability) of each observation from its nested mean. Estimates of mixed-effect model explained more in Table 1 and Fig. 1. $P$-values less than 0.05 were considered statistically significant. All analyses were conducted using STATA V.14.2 statistical software package.

\section{Intra- and inter-examiners calibration}

Inter and intra examiner reliabilities were conducted for the 2 examiners in this study. We were able to exceed the number of calibrations recommended by Fleiss [44] and the 2 examiners assessed BW radiographs for 80 randomly selected patients, measuring the alveolar bone level from the most coronal point of the crestal bone to the most apical point of the CEJ on the mesial and distal surfaces of posterior teeth with the measuring ruler being parallel to the root of each surface. The measurements were repeated one week later with the initial reading being blinded. To achieve a high consistency, each examiner repeated the measurements until we achieved a high degree of agreement between the readings of the same set. Further, inter-examiner reliability test was conducted to eliminate the possibility of chance agreement.
Two-way random-effects [45] intra class correlation coefficient (ICC) test was performed to check both intraand inter-examiner reliabilities using STATA V.14.2 statistical software. ICC agreement is interpreted as poor if it scores less than 0.40 , fair between 0.40 to 0.59 , good between 0.60 to 0.74 , and excellent if it scores between 0.75 and 1.00 [46].

\section{Radiographic discrepancy}

We wanted to measure the expected magnification discrepancy of the $\mathrm{x}$-ray machines that were used to take the radiographs of our sample of interest. A random sample of $22 \mathrm{BW}$ radiographs were selected and measured for the widths of the implants then compared to the true measurements provided by the clinician in the patients' medical records. The mean of radiographic measures was 4.5 $( \pm 0.47)$ while the mean of real measurements provided by the manufacture was $4.36( \pm 0.49)$.

We expected an amount of almost 15\% magnification error that would affect our measurements. This magnification error was taken into account for generating variables based on periodontal disease case definition. Based on the AAP Task Force Report 2015, the earliest sign of mild periodontitis on radiographs is to observe bone loss (measured from CEJ to crestal bone) that is equal to or greater than $2 \mathrm{~mm}$ and less than or equal to $3 \mathrm{~mm}$ without any recommendations about magnification error correction [39].

We adjusted for this error by incorporating $15 \%$ for every $1 \mathrm{~mm}$ in case definition variables generated. For instance, if a real measurement from CEJ to crestal bone is $1.8 \mathrm{~mm}$, which is not an indication of mild periodontitis, the radiograph measurement for that site is expected to be $1.8 \times 1.15=2.07 \mathrm{~mm}$ which might lead to overestimation of the diseases if we used $2 \mathrm{~mm}$ as the cutoff. Hence, we generated case definitions of periodontitis based on this expected radiography magnification error and for the example mentioned, a cutoff of $2.3 \mathrm{~mm}$ (corrected for radiographic magnification error) would not result in overestimation of the disease. We also generated periodontitis case definition based on the recommendation by AAP Task Force Report 2015 and compared the two cut-offs for sensitivity and false positive rate (Fig. 2). The two cut-offs did not significantly differ.

Table 1 Multi-level Mixed-effect model estimates

\begin{tabular}{ll}
\hline Fixed-effect Model & Intercept (grand mean) for whole sample \\
\hline Random-effect Model & Allows variability between individuals, teeth, and sites \\
SD Individuals & SD of each individual's mean from the overall grand mean \\
SD Teeth & SD of each tooth's mean from its individual's mean \\
SD Sites & SD of each observation (site) from its tooth's mean \\
\hline
\end{tabular}




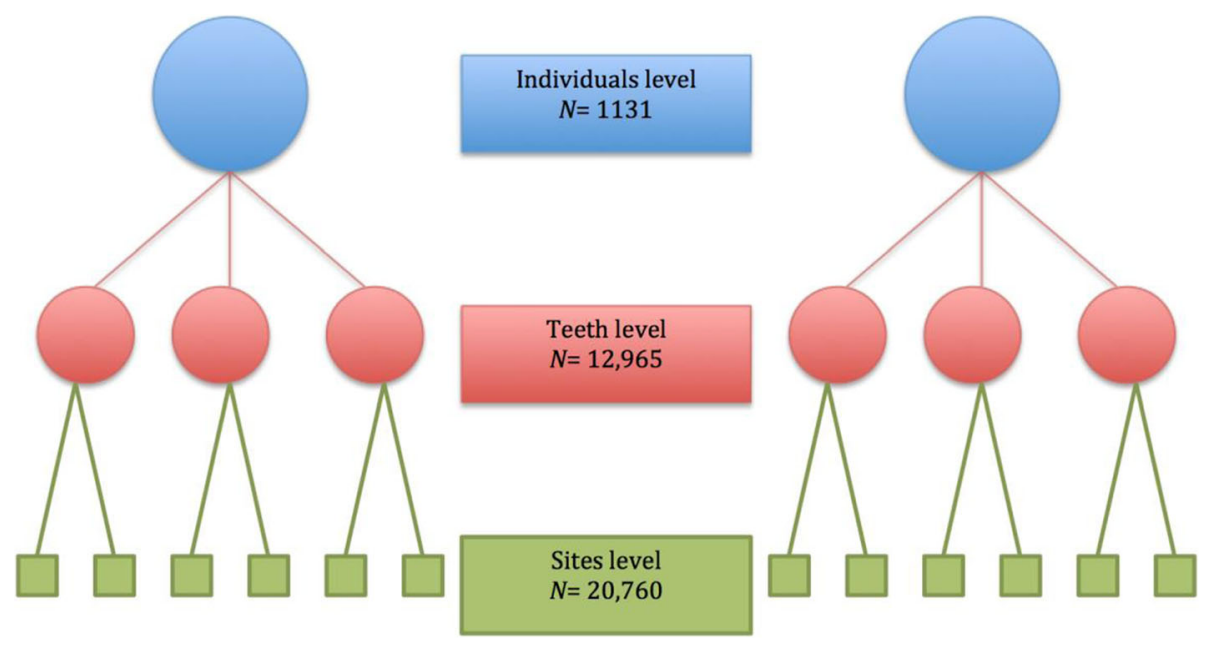

Fig. 1 Multi-level Mixed-effect model

\section{Results}

Table 2 presents results and randomly selected teeth for calibration testing.

\section{Descriptive statistics}

A total of 1131 individuals were included in the analysis with a mean alveolar bone level of $1.30 \mathrm{~mm}( \pm 0.006)$. Mean bone level ranged between $0.77 \mathrm{~mm}( \pm 0.006)$ for the youngest group to $2.04 \mathrm{~mm}( \pm 0.019)$ for the oldest. $55 \%$ of the sample was composed of females with a mean bone level of $1.26 \mathrm{~mm}( \pm 0.008)$ compared to $45 \%$ males with a mean bone level of $1.34( \pm 0.009)$. White race composed $36.5 \%$ of the sample, followed by Other
(22.1\%), Unknown (20.5\%), African American (9.0\%), and Asian (7.5\%). Table 3 presents descriptive statistics for the whole sample.

\section{Severity of the disease and proportions of case definitions}

Overall periodontitis prevalence for the sample was 55.5\% $( \pm 1.4 \%)$. Moderate periodontitis prevalence was $20.7 \%( \pm$ $1.2 \%)$, while $2.8 \%( \pm 0.5 \%)$ of the whole sample had severe periodontitis. All three case definitions were highest among 65+ year-old, males, former smokers, having CVD, and stage 2 hypertension subjects. More detailed prevalence of each case definition across different groups is also

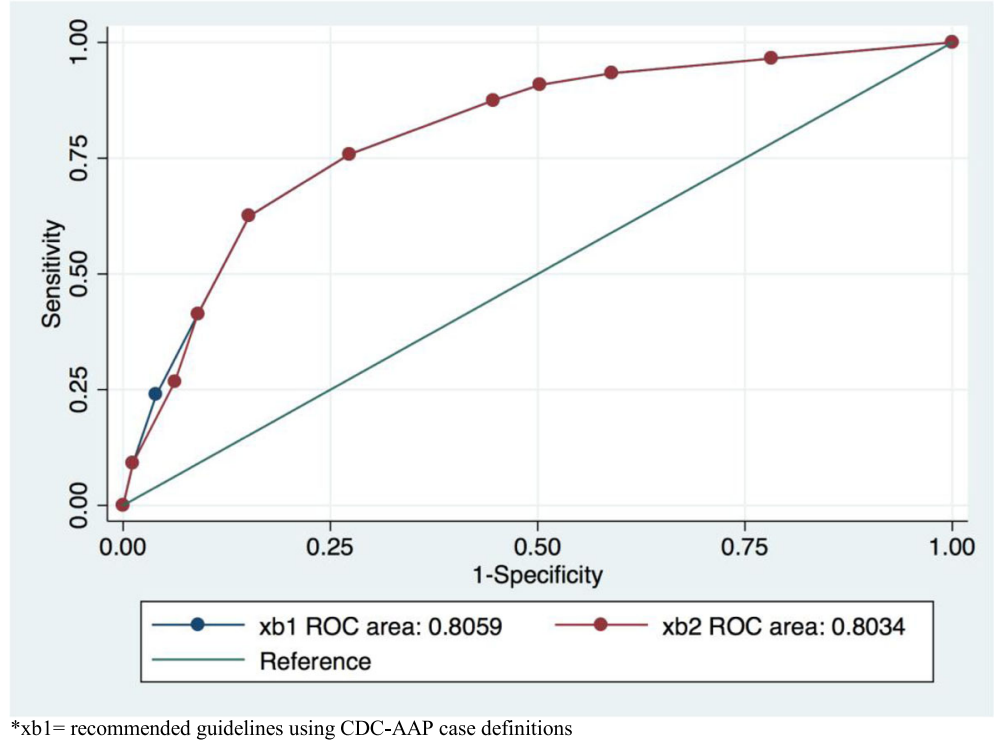

$* x \mathrm{~b} 2=$ measurements corrected for radiographic discrepancy

Fig. 2 ROC curve of comparing CDC-AAP case definitions of periodontitis to $15 \%$ corrected measurements for radiographic magnification. ${ }^{*}$ xb1 $=$ recommended guidelines using CDC-AAP case definitions. * xb2 = measurements corrected for radiographic discrepancy 
Table 2 Intra and inter examiner reliability

\begin{tabular}{lllll}
\hline Examiner & Site/Tooth & ICC Individual $(95 \% \mathrm{Cl})$ & ICC Average $(95 \% \mathrm{Cl})$ & $P$ value \\
\hline Intra M & M3 & $0.92(0.87-0.95)$ & $0.96(0.93-0.97)$ & $P<0.0001$ \\
Intra H & M3 & $0.92(0.86-0.95)$ & $0.95(0.92-0.97)$ & $P<0.0001$ \\
Inter M \&H & M3 & $0.80(0.68-0.87)$ & $0.88(0.81-0.93)$ & $P<0.0001$ \\
Inter M \&H & D13 & $0.95(0.92-0.97)$ & $0.97(0.95-0.98)$ & $P<0.0001$ \\
\hline
\end{tabular}

$\mathrm{N}=80$ subjects. Examiner $1(\mathrm{M})$, had 0.92 agreement $(95 \% \mathrm{Cl} 0.87-0.95)$ for repeated individual measurements and 0.96 (95\% $\mathrm{Cl} 0.93-0.97)$ for averages agreement for intra-examiner reliability comparing the first and second times measurements of alveolar bone level for the mesial site of tooth number 3 for the same subset. Examiner $2(\mathrm{H})$, had an agreement of $0.92(95 \% \mathrm{Cl} 0.86-0.95)$ for individual measurements and $0.96(95 \% \mathrm{Cl} 0.92-0.97)$ for averages agreement for the same variable. We also had excellent agreement for inter-examiner reliability between the two examiners. For example, consistency of agreement for interexaminer reliability comparing the alveolar bone level measurement on the mesial site of tooth number 3 is 0.80 (95\% Cl $0.68-0.87)$ for individual measurements and $0.88(95 \% \mathrm{Cl} 0.81-0.93)$ for average agreement for the same subset. Another example of higher agreement is shown for the distal side of tooth number 13

presented in Table 3. Furthermore, Fig. 3 illustrates prevalence of mild, moderate, and severe periodontitis across different age groups and genders.

\section{Adjusted estimates (multi-variable analysis)}

All variables included in the multi-variable model had significant associations with the outcome except for African American race, diabetes, CVD, and hypertension (they were significant in bivariate analyses). Mean increase in bone loss was higher for older age groups compared to younger age groups with $65+$ year-old exhibiting the highest amount of bone loss, adjusting for sex, race, household income, BMI, smoking, reported CVD, diabetes, and hypertension. Males had higher amounts of bone loss than females (Mean difference $=0.096 \mathrm{~mm}$ [95\% CI: 0.04, 0.14 . $P$-value $<0.001])$, Asian race had higher bone loss compared to White race (Mean difference $=0.23 \mathrm{~mm}[95 \% \mathrm{CI}$ : $0.13,0.33$. $P$-value $<0.001]$ ), and higher household income was also associated with reduced amount of bone loss compared to lower income (Mean difference $=-0.06 \mathrm{~mm}$ [95\% CI: $-0.11,-0.007$. P-value < 0.026]). For BMI, the association was not significant for any categories except for the obese group which showed a significant decline in bone loss compared to the normal weight group equal to - $0.13 \mathrm{~mm}$ (95\% CI: $(-0.22)-(-0.04) . P$-value $=0.003)$. We introduced interaction terms to assess any effect measure modification between BMI and other covariates. We did not find any significant interactions except for median household income and BMI. It showed a decreased amount of bone loss for obese subjects who also had higher than median household income (Mean difference $=$ $-0.25 \mathrm{~mm}$ [95\% CI: $-0.38,-0.12$. P-value <0.001]). Compared to never smokers (reference group), current smokers had higher amounts of bone loss than former smokers. Table 4 provides details of each adjusted mean change in bone level (bone loss) for all variables included in the analyses. For the random effect part, we found that estimates (mean change), compared to their nested means, varied between individuals and teeth by $0.164 \mathrm{~mm}(95 \%$ CI: $0.15,0.18$ ) and $0.066 \mathrm{~mm}$ (95\% CI: 0.060, 0.072), respectively. Random-effect coefficients are also provided in Table 4.

\section{Discussion}

Our results are in agreement with similar studies of prevalence of periodontal diseases among different groups that exhibit specific features and risk factors to periodontal diseases. This is the first time to use Harvard School of Dental Medicine records with this number of patients. A study conducted by Eke et al. in 2012 to evaluate the prevalence of periodontitis in adults in 2009-2010 showed, as in our study, that older age groups have a higher risk and proportion of periodontal diseases compared to younger age groups [19]. Our results indicate that males have a higher risk of developing periodontal diseases with significantly higher alveolar bone loss compared to females and this result coincides with similar results reported in literature indicating males having higher risk of developing the disease $[15,19,47]$. Many studies have reported that smoking is a primary predictor of periodontal diseases [14, 48-52]. In our study, current and former smokers had increased mean alveolar bone loss compared to never smokers (Table 4).

In our study, subjects with higher than median household income were associated with $0.06 \mathrm{~mm}$ lower rate of bone loss compared to subjects with lower than median income (95\% CI: $-0.11,-0.007, p$-value $=0.026)$. Observations of higher risk to periodontal diseases to poverty and low household income have been reported in multiple studies in the literature $[15,53]$. Our results also showed significant reduction in bone loss also for individuals who were categorized as obese by BMI. Limitations, however, exist for BMI, as a sole indicator for obesity; BMI measurements may be misleading because it is a measure for excess weight not excess body fat [54]. Hence, interpretation of BMI associated estimates to the outcome should be interpreted cautiously. We further analyzed this observation to check for any misclassification. Since median household income was the only variable that was associated with decreased risk of bone loss, we created different interaction terms 
Table 3 Prevalence of mild, moderate, and severe periodontitis among different groups of patients visiting HSDM

\begin{tabular}{|c|c|c|c|c|c|c|c|c|c|}
\hline \multicolumn{10}{|l|}{ Percentage (\%) } \\
\hline & $N(\%)$ & Mild & SE & Moderate & SE & Severe & SE & $M A B L^{*}(m m)$ & SE \\
\hline Total & $1131(100.0)$ & 55.5 & 1.4 & 20.7 & 1.2 & 2.8 & 0.5 & 1.30 & 0.006 \\
\hline \multicolumn{10}{|l|}{ Age Groups (yrs) } \\
\hline$<30$ & $247(21.8)$ & 17.0 & 2.3 & 1.2 & 0.7 & 0.0 & $\mathrm{n} / \mathrm{a}$ & 0.77 & 0.006 \\
\hline $30-34$ & $108(9.5)$ & 33.3 & 4.5 & 3.7 & 1.8 & 0.9 & 0.9 & 0.90 & 0.012 \\
\hline $35-49$ & $305(27.0)$ & 51.8 & 2.8 & 12.7 & 1.9 & 1.9 & 0.8 & 1.24 & 0.010 \\
\hline $50-64$ & $300(26.5)$ & 80.6 & 2.2 & 37.3 & 2.8 & 4.3 & 1.1 & 1.80 & 0.013 \\
\hline $65+$ & $171(15.1)$ & 86.5 & 2.6 & 44.5 & 3.8 & 7.0 & 1.9 & 2.04 & 0.019 \\
\hline \multicolumn{10}{|l|}{ Gender } \\
\hline Male & $508(44.9)$ & 57.0 & 2.2 & 24.1 & 1.9 & 4.3 & 0.9 & 1.34 & 0.009 \\
\hline Female & $623(55.1)$ & 54.1 & 1.9 & 18.0 & 1.5 & 1.6 & 0.5 & 1.26 & 0.008 \\
\hline \multicolumn{10}{|l|}{ Race } \\
\hline White & $413(36.5)$ & 56.1 & 2.4 & 20.3 & 1.9 & 2.6 & 0.7 & 1.30 & 0.009 \\
\hline African American & $100(8.8)$ & 53.0 & 5.0 & 27.0 & 4.4 & 9.0 & 2.8 & 1.36 & 0.028 \\
\hline Asian & $85(7.5)$ & 62.3 & 5.2 & 29.4 & 4.9 & 1.1 & 1.1 & 1.43 & 0.020 \\
\hline Other & $250(22.1)$ & 58.0 & 3.1 & 20.0 & 2.5 & 1.6 & 0.7 & 1.29 & 0.012 \\
\hline Unknown & $283(25.0)$ & 48.2 & 3.2 & 15.1 & 2.3 & 3.0 & 1.1 & 1.24 & 0.013 \\
\hline \multicolumn{10}{|c|}{ Median Household Income } \\
\hline Lower than median & $510(45.1)$ & 55.1 & 2.2 & 22.1 & 1.8 & 3.9 & 0.8 & 1.32 & 0.009 \\
\hline Higher than median & $621(54.9)$ & 55.5 & 1.9 & 19.4 & 1.6 & 1.9 & 0.5 & 1.28 & 0.007 \\
\hline \multicolumn{10}{|l|}{ Body Mass Index } \\
\hline Underweight & $27(2.4)$ & 18.5 & 7.6 & 11.1 & 6.1 & 0.0 & $n / a$ & 0.92 & 0.031 \\
\hline Normal & $413(36.5)$ & 52.5 & 2.4 & 19.1 & 1.9 & 2.6 & 0.8 & 1.23 & 0.009 \\
\hline Overweight & $263(23.2)$ & 60.8 & 3.0 & 23.2 & 2.6 & 2.2 & 0.9 & 1.40 & 0.013 \\
\hline Obese & $137(12.1)$ & 59.1 & 4.2 & 23.4 & 3.6 & 3.6 & 1.6 & 1.45 & 0.021 \\
\hline Not reported & $291(25.7)$ & 56.0 & 2.9 & 20.3 & 2.3 & 3.4 & 1.0 & 1.30 & 0.011 \\
\hline \multicolumn{10}{|l|}{ Smoking Status } \\
\hline Never smoker & $668(59.0)$ & 49.5 & 1.9 & 15.8 & 1.4 & 2.3 & 0.6 & 1.19 & 0.007 \\
\hline Former smoker & $141(12.4)$ & 70.2 & 3.8 & 41.1 & 4.1 & 4.2 & 1.7 & 1.72 & 0.021 \\
\hline Current Smoker & $82(7.2)$ & 58.5 & 5.4 & 19.5 & 4.4 & 2.4 & 1.70 & 1.41 & 0.023 \\
\hline Not Reported & $240(21.2)$ & 61.6 & 3.1 & 22.5 & 2.7 & 3.3 & 1.1 & 1.38 & 0.013 \\
\hline \multicolumn{10}{|l|}{ Diabetes } \\
\hline Yes & $60(5.3)$ & 75.0 & 5.6 & 40.0 & 6.3 & 6.7 & 3.2 & 1.81 & 0.038 \\
\hline No & $1071(94.7)$ & 54.2 & 1.5 & 19.6 & 1.2 & 2.6 & 0.5 & 1.28 & 0.006 \\
\hline \multicolumn{10}{|l|}{ CVD } \\
\hline Yes & $132(11.7)$ & 79.5 & 3.5 & 32.6 & 4.1 & 3.0 & 1.5 & 1.66 & 0.020 \\
\hline No & $999(88.3)$ & 52.1 & 1.5 & 19.1 & 1.2 & 2.8 & 0.5 & 1.26 & 0.006 \\
\hline \multicolumn{10}{|l|}{ Hypertension } \\
\hline Normal & 346 (30.6) & 46.8 & 2.6 & 15.6 & 1.9 & 1.4 & 0.6 & 1.18 & 0.009 \\
\hline Elevated & $157(13.9)$ & 54.1 & 3.9 & 21.6 & 3.2 & 3.8 & 1.5 & 1.35 & 0.016 \\
\hline Stage 1 & 281 (24.9) & 59.7 & 2.9 & 24.5 & 2.5 & 2.1 & 0.8 & 1.37 & 0.012 \\
\hline Stage 2 & $125(11.0)$ & 70.4 & 4.1 & 31.2 & 4.1 & 8.0 & 2.4 & 1.61 & 0.023 \\
\hline Not reported & 222 (19.6) & 55.4 & 3.3 & 17.1 & 2.5 & 2.2 & 0.9 & 1.23 & 0.013 \\
\hline
\end{tabular}




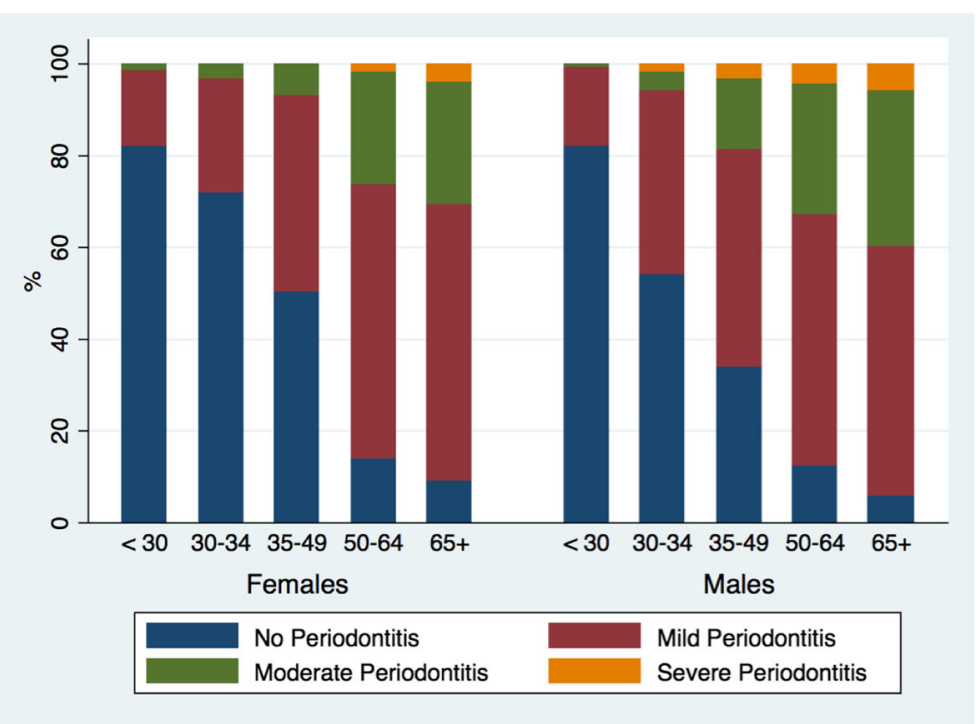

Fig. 3 Prevalence of mild, moderate, and severe periodontitis over different age groups and gender

between median income variable and different predictors. We found that subjects who were obese with higher than median household income had $0.25 \mathrm{~mm}$ lower rate of bone loss (95\% CI: $-0.38,-0.12 . p$-value $<0.001$ ) compared to individuals who had normal weight and low income. This observation suggests that subjects with physiological risk factors would have better health and less adverse outcomes if they had had higher incomes. Social determinants of health may play a crucial role in this observation especially in its geographic, socioeconomic status, and educational backgrounds. Further analysis of social determinants of health is a necessity to understand all factors participating in the development of diseases and their associated risk factors.

One of the strengths of the study is helps to identify patient groups within a closed system (HSDM clinics) with higher oral health needs. Identifying those who come from areas with low median household income can play a key factor in planning treatment, offering patients more services, and, on a larger scale, searching for ways to enhance the access to healthcare system in those areas. Another strength of this study is that measuring protocol was carefully calibrated with an overall excellent inter- and intra-examiner reliability testing.

There are definite limitations, however, focusing on posterior teeth and using only BW radiographs in school records, is one way to conduct a partial mouth periodontal examination (PMPE). PMPE shows tendencies to underestimate prevalence of periodontal diseases when compared to full mouth periodontal examination (FMPE) $[55,56]$. Furthermore, BW radiographs have a limitation in detecting craters, furcation involvements, and different angular defects [57-61] which would result in underestimating the prevalence of the diseases. More precise radiography techniques and periodontal diseases measuring protocols would overcome some of the limitations of this study. Another limitation is several factors should be considered in the future when we study the relationship between household income/systemic diseases and bone loss such as background characteristics, number of visits, oral hygiene and plaque index.

\section{Conclusions}

Although limitations exist in our study, results of this study indicate that different predictive factors have different risks of the progression of periodontal diseases. Primary factors that were associated with higher rates of bone loss were older age, male, Asian racial group, and smoking. Moreover, low income could be one barrier for accessing healthcare systems, dental or medical in general, and thus may play an important role in determining the severity and prevalence of diseases. Our results show that individuals with high household income had lower prevalence of periodontal diseases and lower amount of bone loss compared to individuals with low household income. This manifestation of protective effect by high household income on the amount of bone loss can be powerful to the degree that income can influence the outcome even for individuals who had higher risk of developing the disease. Further analysis of social determinants of health is a necessity to understand all factors participating in the development of diseases and their associated risk factors. Public 
Table 4 Adjusted mean alveolar bone loss $(\mathrm{mm})$ with different predictors included in the model (multi-variable analysis)

\begin{tabular}{|c|c|c|c|c|}
\hline Variables & Adjusted MABL (mm)* & $95 \% \mathrm{CI}$ & $p$-value & \\
\hline \multicolumn{5}{|l|}{$<30$ (reference) } \\
\hline $30-34$ & 0.20 & $(0.11-0.30)$ & $<0.001$ & \\
\hline $35-49$ & 0.43 & $(0.36-0.50)$ & $<0.001$ & \\
\hline $50-64$ & 0.87 & $(0.79-0.95)$ & $<0.001$ & \\
\hline $65+$ & 1.09 & $(0.99-1.18)$ & $<0.001$ & \\
\hline \multicolumn{5}{|l|}{ Female (reference) } \\
\hline Male & 0.096 & $(0.04-0.14)$ & $<0.001$ & \\
\hline \multicolumn{5}{|l|}{ White (reference) } \\
\hline African American & 0.003 & $(-0.09-0.10)$ & 0.949 & \\
\hline Asian & 0.23 & $(0.13-0.33)$ & $<0.001$ & \\
\hline Other & 0.08 & $(0.01-0.15)$ & 0.024 & \\
\hline Unknown & 0.016 & $(-0.05-0.08)$ & 0.641 & \\
\hline Low Underweight & 0.05 & $(-0.22-0.32)$ & 0.709 & \\
\hline \multicolumn{5}{|c|}{ Low Normal (reference) } \\
\hline Low Overweight & -0.02 & $(-0.12-0.08)$ & 0.659 & \\
\hline Low Obese & -0.07 & $(-0.19-0.05)$ & 0.241 & \\
\hline HIgh Underweight & -0.22 & $((-0.442)-(-0.009))$ & 0.041 & \\
\hline High Normal & -0.04 & $(-0.13-0.03)$ & 0.272 & \\
\hline High Overweight & -0.15 & $((-0.25)-(-0.05))$ & 0.004 & \\
\hline High Obese & -0.25 & $((-0.38)-(-0.12))$ & $<0.001$ & \\
\hline \multicolumn{5}{|c|}{ Never smoker (reference) } \\
\hline Former smoker & 0.154 & $(0.07-0.23)$ & $<0.001$ & \\
\hline Current Smoker & 0.157 & $(0.05-0.25)$ & 0.002 & \\
\hline \multicolumn{5}{|l|}{ No (reference) } \\
\hline Yes & 0.020 & $(-0.10-0.14)$ & 0.742 & \\
\hline \multicolumn{5}{|l|}{ Normal (reference) } \\
\hline Elevated & 0.063 & $(-0.019-0.14)$ & 0.137 & \\
\hline Stage 1 & -0.012 & $(-0.08-0.06)$ & 0.739 & \\
\hline Stage 2 & -0.008 & $(-0.10-0.08)$ & 0.860 & \\
\hline \multicolumn{5}{|l|}{ No (reference) } \\
\hline Yes & 0.013 & $(-0.07-0.10)$ & 0.757 & \\
\hline Between Individuals & 0.164 & $(0.15-0.18)$ & $\mathrm{n} / \mathrm{a}$ & \multirow{3}{*}{29} \\
\hline Between Teeth & 0.066 & $(0.060-0.072)$ & $\mathrm{n} / \mathrm{a}$ & \\
\hline Between Sites & 0.17 & $(0.16-0.17)$ & $\mathrm{n} / \mathrm{a}$ & \\
\hline
\end{tabular}

$N=1131$ patients $(20,760$ sites from 12,965 teeth)

*MABL: Mean alveolar bone "loss" in millimeter.

Red color: significant difference $p<0.05$ 
health professionals and clinicians need to collaborate with policy makers to achieve and sustain high quality of healthcare for everyone. Addressing and evaluating areas with low household income for further investigation is necessary to attain and sustain equality of access to the healthcare system.

\section{Abbreviations}

AAP: American Academy of Periodontology; BMI: Body mass index; BW: Bitewing; CEJ: Cement-enamel junction; CVD: Cardiovascular disease; HSDM: Harvard School of Dental Medicine; NHANES: National Health and Nutrition Examination Survey; SES: Socioeconomic status

\section{Acknowledgements}

This project was funded by the Deanship of Scientific Research (DSR), King Abdulaziz University, Jeddah, under grant no. (DF-050-165-1441). The authors, therefore, gratefully acknowledge DSR technical and financial support.

\section{Authors' contributions}

$\mathrm{MH}$ contributed to the study design, data collection, analysis and manuscript writing. ZN contributed to the study design, analysis (tables and analysis), interpretation and manuscript writing. MT, contributed to the study design, interpretation and manuscript editing. HHg, contributed to the study design, and analysis (tables and analysis). MG and HHk contributed to the study design, interpretation and manuscript editing. All authors read and approved the final manuscript.

\section{Funding}

This project was funded by the Deanship of Scientific Research (DSR), King Abdulaziz University, Jeddah, under grant no. (DF-050-165-1441).

\section{Availability of data and materials}

The dataset used during the study are available from the corresponding author upon request.

\section{Ethics approval and consent to participate}

This Study was approved by the office of human research administration, Harvard Faculty of Medicine, [45 CFR 46.101(b) [4]], \#IRB 16-1838. There is no need for any permissions from participations to use the data from AxiUm ${ }^{\circledast}$ after we got the IRB approval since the data were de-identified. The permission from the HDSM to access AxiUm was included in the ethical approval.

\section{Consent for publication}

Not applicable.

\section{Competing interests}

The authors declare that they have no competing interests.

\section{Author details}

${ }^{1}$ Department of Periodontics and Community Dentistry, College of Dentistry, King Saud University, Riyadh, Saudi Arabia. ${ }^{2}$ Department of Oral Health Policy and Epidemiology, School of Dental Medicine, Harvard University, Boston, MA, USA. ${ }^{3}$ Pre-doc student, School of Dental Medicine, Harvard University, Boston, MA, USA. ${ }^{4}$ Department of Oral Medicine, Infection, and Immunity, School of Dental Medicine, Harvard University, Boston, MA, USA. ${ }^{5}$ Department of Applied Oral Sciences, Center for Clinical and Translational Research, The Forsyth Institute, Cambridge, MA, USA. 'Department of Dental Public Health, Faculty of Dentistry, King Abdulaziz University, Jeddah, Saudi Arabia.

Received: 21 June 2019 Accepted: 9 October 2019

Published online: 21 November 2019

\section{References}

1. CDC. Periodontal Disease. 2015; Available from: https://www.cdc.gov/ oralhealth/periodontal_disease/

2. Theilade $E$. The non-specific theory in microbial etiology of inflammatory periodontal diseases. J Clin Periodontol. United States. 1986;13(10):905-11.

3. Haffajee AD, Socransky SS. Microbial etiological agents of destructive periodontal diseases. Periodontol 2000. Denmark. 1994 Jun;5:78-111.
4. Preus H, Zambon JJ. The natural history of periodontal disease. The correlation of selected microbiological parameters with disease severity in Sri Lankan tea workers The natural history of periodontal disease The correlation of selected microbiological. 1995;(October 2015).

5. Kinane DF, Preshaw PM, Loos BG. Host-response: understanding the cellular and molecular mechanisms of host-microbial interactions--consensus of the Seventh European Workshop on Periodontology. J Clin Periodontol. United States; 2011 Mar;38 Suppl 11:44-48.

6. Flemmig TF. Periodontitis. Ann Periodontol United States. 1999 Dec;4(1):32-8.

7. Socransky SS, Haffajee AD, Goodson JM, Lindhe J. New concepts of destructive periodontal disease. J Clin Periodontol. United States. 1984 Jan;11(1):21-32.

8. Albandar JM. A 6-year study on the pattern of periodontal disease progression. J Clin Periodontol. United States. 1990 Aug;17(7 Pt 1):467-71.

9. Albandar JM, Rise J, Gjermo P, Johansen JR. Radiographic quantification of alveolar bone level changes. A 2-year longitudinal study in man. J Clin Periodontol. United States; 1986 Mar;13(3):195-200.

10. Nomura Y, Morozumi T, Nakagawa T, Sugaya T, Kawanami M, Suzuki F, et al. Site-level progression of periodontal disease during a follow-up period. PLoS One United States. 2017;12(12):e0188670.

11. Gilthorpe MS, Zamzuri AT, Griffiths GS, Maddick IH, Eaton KA, Johnson NW. Unification of the "burst" and "linear" theories of periodontal disease progression: a multilevel manifestation of the same phenomenon. J Dent Res. United States. 2003 Mar;82(3):200-5.

12. Cekici A, Kantarci A. Hasturk H. Dyke TE Van periodontal disease. 2015; 64(1):57-80

13. Albandar JM, Rams TE. Risk factors for periodontitis in children and young persons. Periodontol 2000. Denmark. 2002;29:207-22

14. Nunn ME. Understanding the etiology of periodontitis: an overview of periodontal risk factors. Periodontol 2000. Denmark. 2003;32:11-23.

15. Dye BA, Tan S, Smith V, Lewis BG, Barker LK, Thornton-Evans G, et al. Trends in oral health status: United States, 1988-1994 and 1999-2004. Vital Health Stat 11. 2007:(248):1-92.

16. Eke PI, Dye BA, Wei L, Slade GD, Thornton-Evans GO, Borgnakke WS, et al. Update on prevalence of periodontitis in adults in the United States: NHANES 2009 to 2012. J Periodontol. United States. 2015;86(5):611-22.

17. Eke PI, Wei L, Borgnakke WS, Thornton-Evans G, Zhang X, Lu H, et al. Periodontitis prevalence in adults $>/=65$ years of age, in the USA Periodontol 2000. Denmark. 2016:72(1):76-95.

18. Natto ZS, Al-Zahrani MS. Periodontal bone loss and self-reported medical conditions in a dental school patient population. J Int Acad Periodontol. 2010;12(4):104-9.

19. Eke PI, Dye BA, Wei L, Thornton-Evans GO, Genco RJ. Prevalence of periodontitis in adults in the United States: 2009 and 2010. J Dent Res. United States. 2012;91(10):914-20.

20. Albandar JM. Periodontal diseases in North America. Periodontol 2000. Denmark. 2002;29:31-69.

21. Abdellatif HM, Burt BA. An epidemiological investigation into the relative importance of age and oral hygiene status as determinants of periodontitis. J Dent Res United States. 1987;66(1):13-8.

22. Albandar JM. Global risk factors and risk indicators for periodontal diseases. Periodontol 2000. Denmark. 2002;29:177-206.

23. Thomson WM, Slade GD, Beck JD, Elter JR, Spencer AJ, Chalmers JM. Incidence of periodontal attachment loss over 5 years among older south Australians. J Clin Periodontol. United States. 2004;31(2):119-25.

24. Humphrey LL, Fu R, Buckley DI, Freeman M, Helfand M. Periodontal disease and coronary heart disease incidence: a systematic review and metaanalysis. J Gen Intern Med United States. 2008;23(12):2079-86.

25. Preshaw PM, Alba AL, Herrera D, Jepsen S, Konstantinidis A, Makrilakis K, et al. Periodontitis and diabetes: a two-way relationship. Diabetologia Germany. 2012;55(1):21-31.

26. Winning L, Linden GJ. Periodontitis and systemic disease: association or causality? Curr oral heal reports. Switzerland. 2017;4(1):1-7.

27. NIDCR. Periodontal Disease. 2014; Available from: https://www.nidcr.nih.gov/ DataStatistics/ByPopulation/Adults/

28. Marcenes W, Kassebaum NJ, Bernabe E, Flaxman A, Naghavi M, Lopez A, et al. Global burden of oral conditions in 1990-2010: a systematic analysis. J Dent Res. United States. 2013;92(7):592-7.

29. Murray CJL, Salomon JA, Mathers CD, Lopez AD, Organization WH. Summary measures of population health : concepts, ethics, measurement and applications. Geneva World Heal Organ [Internet]. 2002; Available from: http://www.who.int/iris/handle/10665/42439 
30. Zaki H, Hoffmann KR, Hausmann E, Scannapieco FA. Is Radiologic Assessment of Alveolar Crest Height Useful to. 2016;59(4):859-72.

31. Jeffcoat MK, Williams RC. Relationship between linear and area measurements of radiographic bone levels utilizing simple computerized techniques. J Periodontal Res United States. 1984;19(2):191-8.

32. Jeffcoat MK, Jeffcoat RL, Williams RC. A new method for the comparison of bone loss measurements on non-standardized radiographs. J Periodontal Res. United States. 1984;19(4):434-40.

33. Hausmann E, Allen K, Carpio L, Christersson LA, Clerehugh V. Computerized methodology for detection of alveolar crestal bone loss from serial intraoral radiographs. J Periodontol. United States. 1992;63(8):657-62.

34. Fredriksson M, Zimmerman M, Martinsson T. Precision of computerized measurement of marginal alveolar bone height from bite-wing radiographs. Swed Dent J Sweden. 1989;13(4):163-7.

35. U.S. Census Bureau. 2012-2016 American community survey 5-year estimates. 2016; Available from: https://www.census.gov/about.html

36. Savage A, Eaton KA, Moles DR, Needleman I. A systematic review of definitions of periodontitis and methods that have been used to identify this disease. J Clin Periodontol. United States. 2009;36(6):458-67.

37. Laurell L, Romao C, Hugoson A. Longitudinal study on the distribution of proximal sites showing significant bone loss. J Clin Periodontol. United States. 2003;30(4):346-52.

38. Sadeghi R. Prevalence of aggressive periodontitis in 15-18 year old schoolchildren in Tehran. Iran Community Dent Health England. 2010;27(1):57-9.

39. AAP Board of Trustees. American Academy of Periodontology Task Force Report on the Update to the 1999 Classification of Periodontal Diseases and Conditions. J Periodontol. United States. 2015;86(7):835-8.

40. Natto ZS, Abu Ahmad RH, Alsharif LT, Alrowithi HF, Alsini DA, Salih HA, et al. Chronic periodontitis case definitions and confounders in periodontal research: a systematic assessment. Biomed Res Int. 2018;2018:4578782 Epub 2019/01/10

41. Natto ZS, Almeganni N, Alnakeeb E, Bukhari Z, Jan R, lacono VJ. PeriImplantitis and Peri-implant Mucositis case definitions in dental research: a systematic assessment. The Journal of oral implantology. 2019;45(2):127-31 Epub 2018/12/18.

42. CDC. About Adult BMI [Internet]. Division of Nutrition, Physical Activity, and Obesity, National Center for Chronic Disease Prevention and Health Promotion. 2017. Available from: https://www.cdc.gov/healthyweight/ assessing/bmi/adult_bmi/index.html

43. American College of Cardiology. New ACC/AHA High Blood Pressure Guidelines Lower Definition of Hypertension [Internet]. 2017. Available from: http://www.acc.org/latest-in-cardiology/articles/2017/11/08/11/47/mon-5 pm-bp-guideline-aha-2017

44. Fleiss JL. The Design and Analysis of Clinical Experiments. 1st ed. 1986. 17-28 p.

45. Koo TK, Li MY. A guideline of selecting and reporting Intraclass correlation coefficients for reliability research. J Chiropr Med United States. 2016;15(2): 155-63.

46. Cicchetti DV. Guidelines, criteria, and rules of thumb for evaluating normed and standardized assessment instruments in psychology. Psychol Assess. 1994;6(4):284-90.

47. Natto ZS, Hameedaldain A. Methodological quality assessment of metaanalyses and systematic reviews of the relationship between periodontal and systemic diseases. Journal of Evidence Based Dental Practice. 2019;19(2): 131-9 Epub 2019/07/22.

48. Bergstrom J, Eliasson S, Dock J. A 10-year prospective study of tobacco smoking and periodontal health. J Periodontol United States. 2000;71(8):1338-47.

49. Eke PI, Zhang X, Lu H, Wei L, Thornton-Evans G, Greenlund KJ, et al. Predicting periodontitis at state and local levels in the United States. J Dent Res. 2016;95(5):515-22

50. Natto ZS, Aladmawy M, Alasqah M, Papas A. Factors contributing to tooth loss among the elderly: a cross sectional study. Singap Dent J. 2014;35:1722 Epub 2014/12/17

51. Natto ZS, Aladmawy M, Alasqah M, Papas A. Is there a relationship between periodontal disease and causes of death? A cross sectional study. Braz Dent J. 2015;26(1):33-8 Epub 2015/02/13

52. Natto ZS, Aladmawy M, Alshaeri HK, Alasqah M, Papas A. Is there a relationship between periodontal conditions and number of medications among the elderly? Ghana Medical Journal. 2016;50(1):9-15.

53. Elter JR, Beck JD, Slade GD, Offenbacher S. Etiologic models for incident periodontal attachment loss in older adults. J Clin Periodontol United States. 1999 Feb;26(2):113-23.
54. CDC. Body Mass Index: Considerations for Practitioners [Internet]. Available from: https://www.cdc.gov/obesity/downloads/bmiforpactitioners.pdf

55. Albandar JM. Underestimation of Periodontitis in NHANES Surveys. 2011; (March):337-41.

56. Eke PI, Thornton-Evans GO, Wei L, Borgnakke WS, Dye BA. Accuracy of NHANES periodontal examination protocols. J Dent Res. United States. 2010 Nov;89(11):1208-13.

57. Bagis N, Kolsuz ME, Kursun S, Orhan K. Comparison of intraoral radiography and cone-beam computed tomography for the detection of periodontal defects: an in vitro study. BMC Oral Health. England. 2015;15:64.

58. Scarfe WC, Azevedo B, Pinheiro LR, Priaminiarti M, Sales MAO. The emerging role of maxillofacial radiology in the diagnosis and management of patients with complex periodontitis. Periodontol 2000. Denmark. 2017;74(1):116-39.

59. Aladmawy MA, Natto ZS, Steffensen B, Levi P, Cheung W, Finkelman M, Ogata Y, Hur Y. A Comparison between Primary and Secondary Flap Coverage in Ridge Preservation Procedures: A Pilot Randomized Controlled Clinical Trial. Biomed Res Int; 2019; 2019:7679319.

60. Natto ZS, Yaghmoor W, Bannuru RR, Nevins M. Identification and efficacy ranking of allograft and Xenograft for extraction and ridge preservation procedures. Int J Periodontics Restorative Dent. 2017;37(5):e253-60.

61. Natto ZS, Parashis A, Steffensen B, Ganguly R, Finkelman MD, Jeong YN. Efficacy of collagen matrix seal and collagen sponge on ridge preservation in combination with bone allograft: a randomized controlled clinical trial. J Clin Periodontol. 2017:44(6):649-59.

\section{Publisher's Note}

Springer Nature remains neutral with regard to jurisdictional claims in published maps and institutional affiliations.
Ready to submit your research? Choose BMC and benefit from:

- fast, convenient online submission

- thorough peer review by experienced researchers in your field

- rapid publication on acceptance

- support for research data, including large and complex data types

- gold Open Access which fosters wider collaboration and increased citations

- maximum visibility for your research: over $100 \mathrm{M}$ website views per year

At $\mathrm{BMC}$, research is always in progress.

Learn more biomedcentral.com/submissions 